\title{
Explorative statistical analysis to identify factors affecting the survival of pygmy hippopotamus (Choeropsis liberiensis) kept in zoological gardens
}

\author{
Francesca Da Rè ${ }^{1}$, Magdalena Graczyk ${ }^{2}$, Piotr Cwiertnia ${ }^{3,4}$, \\ Martino Cassandro ${ }^{1}$, Tomasz Szwaczkowski ${ }^{2}$ \& Ewa Sell-Kubiak ${ }^{2, *}$ \\ ${ }^{1}$ Department of Agronomy, Food, Natural Resources, Animals and Environment, University of \\ Padova, Agripolis, Viale dell'Università 16, 35020, Legnaro, Padova, Italy. \\ ${ }^{2}$ Department of Genetics and Animal Breeding, Poznan University of Life Sciences, \\ Wolynska 33, 60-637 Poznan, Poland. \\ ${ }^{3}$ Municipal Zoological Garden in Plock, Norbertanska 2, 09-402 Plock, Poland . \\ ${ }^{4}$ Zoological Garden in Poznan, Kaprala Wojtka 3, 61-063 Poznan Poland. \\ Corresponding author: sell@up.poznan.pl
}

\begin{abstract}
This study aimed to evaluate the genetic and environmental factors affecting the survival of the pygmy hippopotamus (Choeropsis liberiensis) population kept in zoological gardens, including the estimation of the inbreeding level. Survival was examined at three time points: birth (0-1 days), 1 month (30 days) and 5 years of age. The data were obtained from the Zoological Information Management System, and covered observations on 1196 pygmy hippo, collected between 1873 and April 2016 and grouped into five geographical regions (Africa, Australasia, Europe, USA and Canada, and South America). The analyses were performed using LOGIT and PROBIT transformations of the binominal survival data. No statistically significant differences ( $\mathrm{P}$-value $>0.05$ ) were observed between the results obtained from the two transformations. The survival of individuals was found to decrease with increased level of inbreeding, the most significant effect being on survival at birth. At all three survival time points the highest survival was observed among females. Additionally, the Australasia region showed the highest overall survival. We hypothesize that the environment, climate and similarity of local food to the native diet of pygmy hippo allows animals kept in zoological gardens in that region to perform better than in other regions. The results of this study indicated that it is necessary to exercise vigilance in reducing inbreeding as it negatively impacts survival. This can be achieved by continued efforts to maintain and improve genetic diversity through management of breeding and associated transfer of animals between zoological facilities to reduce relatedness in breeding pairs.
\end{abstract}

KEYWORDS. Pygmy hippo, inbreeding, zoo populations, survival, endangered species.

Da Rè F., Graczyk M., Cwiertnia P., Cassandro M., Szwaczkowski T. \& Sell-Kubiak E. (2018). Explorative statistical analysis to identify factors affecting the survival of pygmy hippopotamus (Choeropsis liberiensis) kept in zoological gardens. Belgian Journal of Zoology 148 (1): 1-12. https://doi.org/10.26496/bjz.2018.15 


\section{Introduction}

The ongoing biodiversity crisis is significantly affecting mammals worldwide. It is estimated that between $21 \%$ and $36 \%$ of existing mammalian species are threatened with extinction (MAY-COLLADO et al. 2011). The primary short-term goal for conservation of endangered species is ensuring survival over a given time period, whereas long-term goals also involve the retention of the genetic variability through successful reproduction, expansion, and maintenance of population viability for eventual reestablishment of wild populations. In this situation, the prime genetic considerations are the avoidance of both inbreeding depression and the chances of fixation of potentially non-adapted genotypes, and the maintenance of a healthy sex ratio in the population. Genetic diversity is essential for conservation of endangered populations, as it is positively correlated with the adaptive capacity of a population (BOOY et al. 2000; OlienOeK 2009). Small populations are at risk of decreasing genetic diversity due to a small number of parents $v$ s founders (RALls \& BALlou 1986; OlieHOEK 2009). Decline in genetic diversity is eventually followed by higher levels of inbreeding, which can cause inbreeding depression (OLIEHOEK 2009). The occurrence of inbreeding depression is related to decrease in vitality and higher susceptibility when populations are exposed to diseases and changing environmental conditions. Also a lower reproductive performance (e.g., higher rate of miscarriages or stillborns), frequent incidents of recessive diseases and presence of lethal genes can be observed in such populations (e.g., SZWACZKOWSKI et al. 2003). The likelihood of inbreeding is related to population size: when population size declines, the probability of mating with relatives increases (RIOUX-PAQUETTE et al. 2011). Therefore, inbreeding remains one of the main concerns for endangered species' conservation efforts, both in the wild and under managed care.

The above-mentioned issues are affecting the pygmy hippopotamus (Choeropsis liberiensis) population kept in zoological gardens. Pygmy hippos in nature are hunted for their meat, but also their natural habitat has been severely reduced by wide-scale deforestation, resulting in a serious population decline. The species is listed as "endangered" on the International Union for Conservation of Nature and Natural Resources Red List, and distribution is limited to fragmented populations in Ivory Coast, Guinea, Liberia and Sierra Leone in West Africa (FLACKE et al. 2015). Thus zoological gardens have begun to play an important role in preserving this species, and they must ensure successful reproduction of captive pygmy hippos (ZSCHOKKE 2002). In the last 40 years, the captive population has remained at 300 to 350 animals and The International Studbook is managed by Zoo Basel, Switzerland (FLACKE et al. 2015).

Despite the need to ensure the survival of animals kept in zoological gardens, little is known about the genetic and environmental factors affecting survival in many populations of these species, including the pygmy hippo. Recently, GRACZYK et al. (2015) reported an average inbreeding level of $5.39 \%$ in this population, FLACKE et al. (2016) published a comprehensive study on various causes of mortality in pygmy hippo kept in zoological gardens, and FLACKE et al. (2017) performed survival analysis on those animals affected by polycystic kidney disease. However, further research is needed to comprehensively evaluate the potential factors affecting survival of pygmy hippo on a global scale in order to identify management and husbandry factors that can help improve population viability.

Thus the aim of this study was to identify genetic and environmental factors affecting the survival of the pygmy hippo population kept in zoological gardens, focusing on effects of sex, inbreeding and geographic region and how these variables affect survival at three time points: at birth, to 1 month and to 5 years of age.

\section{Material and methods}

\section{Population}

The data for this study were extracted in April 2016 from the Zoological Information Management System (ZIMS) database (owned by the non-profit organization Species360), which contains real-time 
TABLE 1

Description of the data structure.

\begin{tabular}{c|c}
\hline Variable & Number of observations \\
\hline Sex & 495 males, 701 females \\
Birth period group & 49 classes ${ }^{1}$ \\
Survival at birth ${ }^{2}$ & 958 alive, $238 \mathrm{dead}$ \\
Survival to 1 month $^{2}$ & 839 alive, 357 dead \\
Survival to 5 years ${ }^{3}$ & 650 alive, 503 dead $^{4}$ \\
\hline
\end{tabular}

Each birth period group contained 16-34 individuals.

2 0-1 day from birth date.

5 years of age.

${ }^{4}$ Animals that were not yet five years of age at the time of the analysis were removed from the dataset (43 animals).

information on animals kept in zoological gardens. The dataset contained information on 1481 pygmy hippo (599 males, 812 females and 70 of unknown sex) born from 1873 to April 2016.

\section{Data editing}

The survival (defined as a binomial $0-1$ trait) was measured at three different time points: birth (0-1 day from birth date), 1 month (30 days) and 5 years of age. In order to perform analysis of those traits the data for this study required records on birth and death dates to establish whether an animal survived to each of the time points. Thus animals were removed from the dataset if they were missing information on birth and/or death date (58 animals). However, this applied only to animals born before 1975 since the average life span of the pygmy hippo in captivity is 40 years (ELTRINGHAM 1999). Animals born in years 1976 to 2016 that were lacking information concerning date of death were assumed to be alive at the time of the analysis. Further, the animals of undetermined sex were removed from the dataset (70 animals) as were animals from zoological gardens whose location was unknown (183 animals) as these records were required for analysis of survival traits. Animals that were not yet 5 years of age at the time of analysis were excluded from survival analysis of that trait (43 animals). The final dataset contained information on 1196 individuals, of which 495 were males and 701 were females born from 1919 to 2016 (Table 1).

Further modification of the dataset focused on creating birth year and geographic region classes as these variables were later included in the statistical models as fixed effects. The number of animals born each year varied from 1 to 20 individuals. Thus to obtain more equal sizes of birth year classes and to avoid classes with very few animals, 49 birth period groups with 16 to 34 animals were created (Table 2). Following GRACZYK et al. (2015), countries from which animals originated were grouped in four geographic regions: I. Australasia; II. Europe; III. North America; and IV. Africa. The data used in this study also had records for animals from South America, which was included in the analysis as region $\mathrm{V}$. Table 3 presents the overview of a number of animals from each country and region and their respective survival rates.

In statistical analysis, evaluation between levels of an effect is often presented as a comparison of all other categories with the category that has the largest effect on a trait of interest. This means that the category or variable with the largest effect is standardized to ' 0 ' to represent baseline, and the remaining levels represent the difference from ' 0 '. The results (see below) indicated that geographical region I (Australasia) and sex $=$ male had the biggest effect on survival traits. Thus remaining regions (II-V) were compared with region I (Australasia) and $\operatorname{sex}=$ female with male $=$ sex. 
TABLE 2

Birth period groups created to obtain homogeneous size classes with 16-34 animals in each class.

\begin{tabular}{ccc|ccc}
\hline $\begin{array}{c}\text { Birth period } \\
\text { group }\end{array}$ & Years & $\begin{array}{c}\text { Number of } \\
\text { animals }\end{array}$ & $\begin{array}{c}\text { Birth period } \\
\text { group }\end{array}$ & Years & $\begin{array}{c}\text { Number of } \\
\text { animals }\end{array}$ \\
\hline $\mathbf{1}$ & $1919-1934$ & 26 & $\mathbf{2 6}$ & 1990 & 23 \\
$\mathbf{2}$ & $1935-1944$ & 25 & $\mathbf{2 7}$ & 1991 & 34 \\
$\mathbf{3}$ & $1945-1955$ & 29 & $\mathbf{2 8}$ & 1992 & 29 \\
$\mathbf{4}$ & $1956-1962$ & 26 & $\mathbf{2 9}$ & 1993 & 24 \\
$\mathbf{5}$ & $1963-1965$ & 27 & $\mathbf{3 0}$ & 1994 & 17 \\
$\mathbf{6}$ & $1966-1969$ & 29 & $\mathbf{3 1}$ & 1995 & 28 \\
$\mathbf{7}$ & $1970-1971$ & 29 & $\mathbf{3 2}$ & 1996 & 19 \\
$\mathbf{8}$ & 1972 & 18 & $\mathbf{3 3}$ & 1997 & 20 \\
$\mathbf{9}$ & 1973 & 16 & $\mathbf{3 4}$ & 1998 & 26 \\
$\mathbf{1 0}$ & 1974 & 20 & $\mathbf{3 5}$ & 1999 & 21 \\
$\mathbf{1 1}$ & 1975 & 19 & $\mathbf{3 6}$ & 2000 & 27 \\
$\mathbf{1 2}$ & 1976 & 29 & $\mathbf{3 7}$ & 2001 & 18 \\
$\mathbf{1 3}$ & 1977 & 28 & $\mathbf{3 8}$ & 2002 & 20 \\
$\mathbf{1 4}$ & 1978 & 25 & $\mathbf{3 9}$ & 2003 & 23 \\
$\mathbf{1 5}$ & 1979 & 24 & $\mathbf{4 0}$ & 2004 & 21 \\
$\mathbf{1 6}$ & 1980 & 25 & $\mathbf{4 1}$ & 2005 & 19 \\
$\mathbf{1 7}$ & 1981 & 24 & $\mathbf{4 2}$ & 2006 & 28 \\
$\mathbf{1 8}$ & 1982 & 28 & $\mathbf{4 3}$ & 2007 & 18 \\
$\mathbf{1 9}$ & 1983 & 26 & $\mathbf{4 4}$ & 2008 & 18 \\
$\mathbf{2 0}$ & 1984 & 32 & $\mathbf{4 5}$ & 2009 & 26 \\
$\mathbf{2 1}$ & 1985 & 25 & $\mathbf{4 6}$ & 2010 & 23 \\
$\mathbf{2 2}$ & 1986 & 25 & $\mathbf{4 7}$ & 2011 & 26 \\
$\mathbf{2 3}$ & 1987 & 26 & $\mathbf{4 8}$ & 2012 & 31 \\
$\mathbf{2 4}$ & 1988 & 16 & $\mathbf{4 9}$ & $2013-2016$ & 34 \\
$\mathbf{2 5}$ & 1989 & 26 & & & \\
\hline & & & & & \\
\hline
\end{tabular}

\section{Statistical analysis}

In this study the mixed model approach was applied. To analyze binomial data a transformation was required. We applied two types of transformations: LOGIT and PROBIT. In short, LOGIT uses logarithmic transformation of binominal data, whereas PROBIT uses cumulative frequencies and it transforms the sigmoid dose-response curve to a straight line that can then be analyzed by regression, either through least squares or maximum likelihood (OTT \& LONGNECKER 2001). The analyses were performed using both the LOGIT and PROBIT data transformation methods in SAS statistical software (SAS Institute 1999). Each of the three survival time points was analyzed with two models.

The first model was as follows: $Y_{i j k l}=\mu+S_{i}+R_{j}+P_{k}+b x_{i j k l}+e_{i j k l}$, where $y_{i j k l}$ is one of the survival traits of $i j k l$-th individual after LOGIT or PROBIT transformation, respectively; $\mu$ is the overall mean, $S_{i}$ is the fixed effect of $i$-th sex ( 2 levels), $R_{j}$ is the fixed effect of $j$-th geographic region (5 levels); $P_{k}$ is the fixed effect of $k$-th birth period (49 levels), $x_{i j k l}$ is the inbreeding coefficient of $i j k l$-th individual, $b$ is the partial linear regression coefficient and $e_{i j k l}$ is the random error connected with $i j k l$-th observation. 
TABLE 3

Number of zoos and animals with percent survival at three different time points (at birth $0-1$ day, to 1 month and 5 years of age) in 45 countries within five geographic regions. The number of zoos and animals for each country represents the total number for the period of the study from 1919 to April 2016.

\begin{tabular}{|c|c|c|c|c|c|c|}
\hline Region & Countries & $\begin{array}{l}\text { Number of } \\
\text { zoos }\end{array}$ & $\begin{array}{l}\text { Number of } \\
\text { animals }\end{array}$ & $\begin{array}{c}\text { Survival } \\
\text { birth (\%) }\end{array}$ & $\begin{array}{c}\text { Survival } \\
1 \text { month (\%) }\end{array}$ & $\begin{array}{c}\text { Survival } \\
5 \text { years }(\%)\end{array}$ \\
\hline \multirow{11}{*}{ Australasia } & Australia & 5 & 25 & 96 & 72 & 60 \\
\hline & India & 1 & 2 & 100 & 50 & 50 \\
\hline & China & 2 & 20 & 65 & 60 & 40 \\
\hline & Indonesia & 6 & 42 & 81 & 74 & 60 \\
\hline & Japan & 2 & 12 & 92 & 83 & 67 \\
\hline & Malaysia & 1 & 3 & 67 & 67 & 0 \\
\hline & Saudi Arabia & 1 & 7 & 71 & 71 & 57 \\
\hline & Singapore & 1 & 26 & 92 & 88 & 62 \\
\hline & Sri Lanka & 1 & 15 & 87 & 87 & 87 \\
\hline & Taiwan & 1 & 3 & 100 & 100 & 100 \\
\hline & Thailand & 4 & 15 & 100 & 100 & 73 \\
\hline Middle East & Arab Emirates & 1 & 1 & 100 & 100 & 0 \\
\hline \multirow{21}{*}{ Europe } & Belgium & 1 & 3 & 67 & 67 & 67 \\
\hline & Croatia & 1 & 2 & 50 & 0 & 0 \\
\hline & Czech Republic & 6 & 53 & 81 & 75 & 53 \\
\hline & Denmark & 3 & 24 & 79 & 71 & 54 \\
\hline & England & 8 & 78 & 79 & 63 & 42 \\
\hline & Estonia & 1 & 3 & 100 & 0 & 0 \\
\hline & France & 4 & 32 & 72 & 53 & 34 \\
\hline & Germany & 16 & 153 & 85 & 80 & 67 \\
\hline & Greece & 1 & 5 & 100 & 80 & 40 \\
\hline & Hungary & 3 & 5 & 80 & 80 & 20 \\
\hline & Italy & 3 & 19 & 84 & 79 & 74 \\
\hline & Lithuania & 1 & 12 & 92 & 58 & 42 \\
\hline & Netherlands & 5 & 35 & 94 & 89 & 74 \\
\hline & Norway & 1 & 7 & 86 & 57 & 29 \\
\hline & Poland & 5 & 35 & 83 & 74 & 51 \\
\hline & Portugal & 2 & 14 & 57 & 36 & 14 \\
\hline & Russia & 2 & 4 & 75 & 75 & 50 \\
\hline & Slovakia & 1 & 9 & 89 & 89 & 67 \\
\hline & Spain & 5 & 22 & 68 & 50 & 50 \\
\hline & Sweden & 1 & 2 & 50 & 50 & 50 \\
\hline & Switzerland & 2 & 90 & 79 & 69 & 58 \\
\hline \multirow{2}{*}{ North America } & Canada & 2 & 13 & 69 & 54 & 46 \\
\hline & USA & 36 & 300 & 77 & 68 & 54 \\
\hline \multirow{5}{*}{ Africa } & Ivory Coast & 1 & 8 & 88 & 75 & 75 \\
\hline & Kenya & 2 & 10 & 90 & 80 & 70 \\
\hline & Nigeria & 1 & 6 & 83 & 50 & 50 \\
\hline & South Africa & 5 & 68 & 69 & 59 & 40 \\
\hline & Tunisia & 1 & 4 & 100 & 100 & 50 \\
\hline \multirow{5}{*}{ South America } & Argentina & 1 & 2 & 0 & 0 & 0 \\
\hline & Chile & 1 & 2 & 100 & 100 & 50 \\
\hline & Cuba & 1 & 1 & 100 & 100 & 100 \\
\hline & Mexico & 1 & 2 & 50 & 0 & 0 \\
\hline & Uruguay & 1 & 2 & 50 & 50 & 0 \\
\hline
\end{tabular}




\section{TABLE 4}

Significance level (P-value) of fixed effects (sex, inbreeding, region, birth period and birth period-region combined effect) used in LOGIT and PROBIT transformation methods for survival at birth (0-1 day), to 1 month and to 5 years of age.

\begin{tabular}{c|c|cc|cc}
\hline \multirow{2}{*}{ Dependent variable } & \multirow{2}{*}{ Fixed effect } & \multicolumn{2}{|c|}{ LOGIT transformation } & \multicolumn{2}{c}{ PROBIT transformation } \\
\cline { 3 - 6 } & & Model 1 & Model 2 & Model 1 & Model 2 \\
\hline \multirow{4}{*}{ Survival at birth } & sex & 0.005 & 0.003 & 0.003 & 0.001 \\
& inbreeding & $<.0001$ & $<.0001$ & $<.0001$ & $<.0001$ \\
& region & 0.011 & - & 0.007 & - \\
& birth period & n.s. & - & n.s. & - \\
& birth period-region & - & n.s. & - & n.s. \\
\hline \multirow{5}{*}{ Survival to 1 month } & sex & 0.014 & 0.001 & 0.013 & $<.0001$ \\
& inbreeding & 0.003 & 0.001 & 0.002 & $<.0001$ \\
& region & 0.007 & - & 0.007 & - \\
& birth period & n.s. & - & n.s. & - \\
& birth period-region & - & n.s. & - & n.s. \\
\hline \multirow{5}{*}{ Survival to 5 years } & sex & 0.019 & 0.001 & 0.017 & 0.001 \\
& inbreeding & 0.005 & $<.0001$ & 0.005 & $<.0001$ \\
& region & 0.03 & - & 0.03 & - \\
& birth period & n.s. & - & n.s. & - \\
& birth period-region & - & n.s. & - & n.s. \\
\hline
\end{tabular}

The second model was as follows: $Y_{i j k}=\mu+S_{i}+[(R P)]_{j}+b x_{i j k}+e_{i j k}$, where $(R P)_{j}$ is the combined effect of $j$-th geographic region and birth period (245 levels), other symbols as above.

The inbreeding coefficient for each animal was extracted from additive relationship matrix using CFC program (SARGOLZAEI et al. 2006) and records of 194 sires and 256 dams. In total the records of 30 sires and 26 dams did not allow estimation of relatedness to the population, and their inbreeding was set to 0 . The average calculated pedigree completeness was 3.18 with a minimum of 1.5 and a maximum of 5.28; this average was calculated only for inbred animals.

\section{Results}

\section{Statistical models}

Effects of sex, inbreeding and geographic region significantly affected survival of pygmy hippo in all models and for all three survival time points, whereas the birth period (model 1) and the birth period-region combined (model 2) had no significant effect on the traits of interest. Moreover, the significance level (based on P-value) of each effect for each of three traits was very similar. The two data transformations, LOGIT and PROBIT, yielded very similar results when comparing model 1 and model 2. The significance levels (based on P-value) of each fixed effect at the three survival time points are presented in Table 4.

The $R^{2}$ used in this study to compare the models was very low overall and varied from 0.5 to 0.7 for model 1 and was equal to 0.18 for model 2 (Table 5).

\section{Estimated effects of sex, inbreeding and geographic region}

Inbreeding had the largest effect on survival at birth (2.63) and the lowest (1.66) on survival to 5 years of age (Table 6). The estimated effect of inbreeding at the three survival time points was lower with the 
TABLE 5

Comparison of the $R^{2}$ for the LOGIT and PROBIT transformation methods for survival at birth (0-1 day), survival to 1 month and survival to 5 years of age.

\begin{tabular}{c|cc|cc}
\hline \multirow{2}{*}{ Dependent variable } & \multicolumn{2}{|c|}{ LOGIT transformation ${ }^{1}$} & \multicolumn{2}{c}{ PROBIT transformation ${ }^{1}$} \\
\cline { 2 - 4 } & Model 1 & Model 2 & Model 1 & Model 2 $^{*}$ \\
\hline Survival at birth & 0.06 & 0.18 & 0.06 & 0.18 \\
Survival to 1 month & 0.05 & 0.18 & 0.05 & 0.18 \\
Survival to 5 years & 0.07 & 0.18 & 0.07 & 0.18 \\
\hline
\end{tabular}

${ }^{1}$ Model 1: inbreeding as linear variable; sex, geographic region and birth period as categorical variables. Model 2: inbreeding as linear variable; sex as class variable, combined effect of original geographic region and birth period as categorical variables.

TABLE 6

Estimated effect of inbreeding on survival at birth (0-1 day), survival to 1 month and survival to 5 years of age of pygmy hippopotamus tested with two models and two transformations.

\begin{tabular}{|c|c|c|c|c|}
\hline \multirow{2}{*}{ Dependent variable } & \multicolumn{2}{|c|}{ LOGIT transformation ${ }^{1}$} & \multicolumn{2}{|c|}{ PROBIT transformation ${ }^{1}$} \\
\hline & Model 1 & Model 2 & Model 1 & Model 2 \\
\hline Survival at birth & 2.63 & 3.52 & 1.58 & 2.11 \\
\hline Survival to 1 month & 1.86 & 2.49 & 1.15 & 1.53 \\
\hline Survival to 5 years & 1.66 & 2.29 & 1.02 & 1.42 \\
\hline
\end{tabular}

${ }^{1}$ Model 1: inbreeding as linear variable; sex, geographic region and birth period as categorical variables. Model 2: inbreeding as linear variable; sex as class variable, combined effect of original geographic region and birth period as categorical variables.

PROBIT than with the LOGIT transformation method. Additionally, the models with birth period and region as separate effects (model 1) showed a smaller estimated effect of inbreeding on all survival traits than did model 2 (Table 6).

The sex of the animal had the largest effect on survival at birth (Fig. 1); however, the differences between sex and the other survival traits used in our analyses were very small. Also, negligible differences were observed for sex effects estimates between model 1 and model 2 for both transformations for each survival trait.

The estimated effect of region at three survival time points was larger with LOGIT than with PROBIT transformation (Fig. 2). Region I (Australasia) had the highest survival for all traits and for both transformation methods (Fig. 2).

\section{Discussion}

This study aimed to explore the potential environmental and genetic factors affecting pygmy hippo survival for three time points: at birth, to 1 month, and to 5 years of age. These quantitative statistical analyses were performed with LOGIT or PROBIT transformation of binominal survival data of 1196 individuals. 

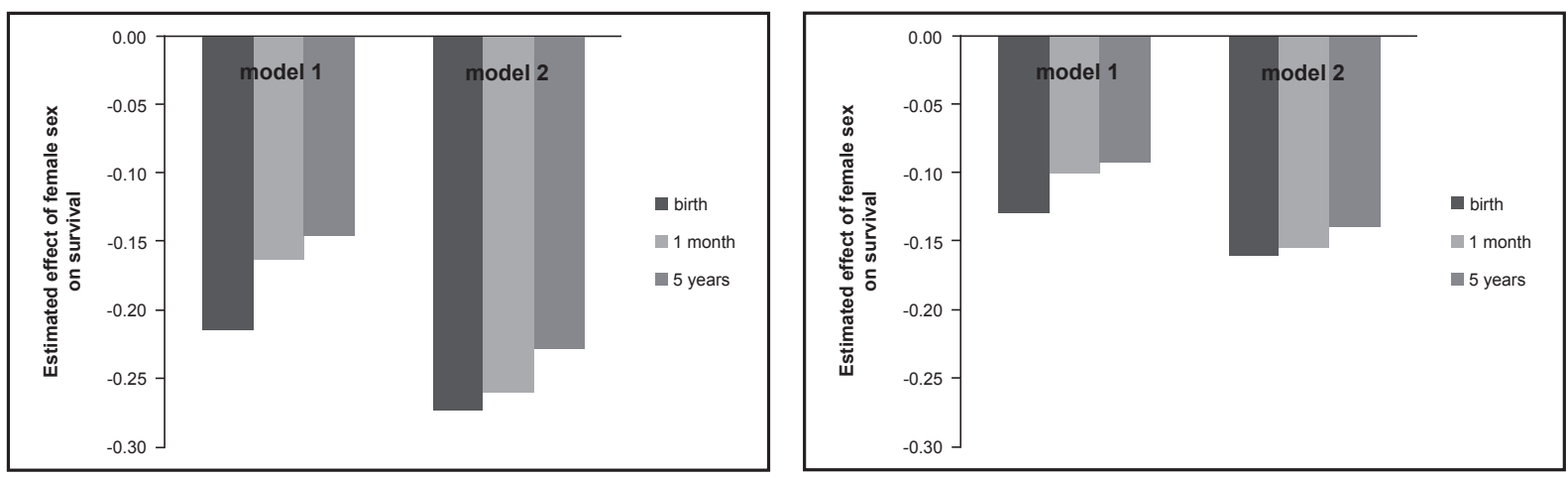

Fig. $1-$ Estimated effect of female $=$ sex on survival at birth $(0-1$ day $)$, survival to 1 month and survival to 5 years of age with LOGIT (A) or PROBIT (B) transformation models. Male $=$ sex is the reference category.

\section{Effect of sex}

This study indicated lower survival in males than in females for all studied survival time points, in particular at birth and then slightly increasing in later stages of life (Fig. 2). Higher survival of females (from birth to 6 months of age) was also observed in earlier studies on pygmy hippo (ZsCHOKKE 2002; PLUHÁČEK \& STECK 2015). The most recent study of FLACKE et al. (2016) based on evaluation of cause of death of 404 animals, also indicated overall high levels of mortality in juveniles, being $33 \%$ in males and $26 \%$ in females, however, they could not find a reason for higher values in males based on their comprehensive study of mortality causes in pygmy hippo. Based on our results from 1196 records and the literature findings, we did a follow up check of our data and it was observed that the inbreeding was on average higher in males $(\sim 0.064)$ than in females $(\sim 0.059)$. Although those figures are not significantly different, they may indicate one of the contributors to lower survival in males than females, since high inbreeding level can cause inbreeding depression leading to overall lower fitness of an individual. It is imperative that in the future, better management of the relationship level between a male and its breeding female is undertaken to avoid further increase of inbreeding in the population.

The higher mortality of pygmy hippo males than females also has consequences for the sex ratio in this population. Studies of ZSCHOKKE (2002) and PLUHÁČEK \& STECK (2015) indicated that the sex ratio in captive pygmy hippo population is highly biased towards females, beginning at birth and continuing towards maturity. In other captive species the opposite has been observed. A study of the possible determinants of skewed natal sex ratios in captive black (Diceros bicornis) and greater one-
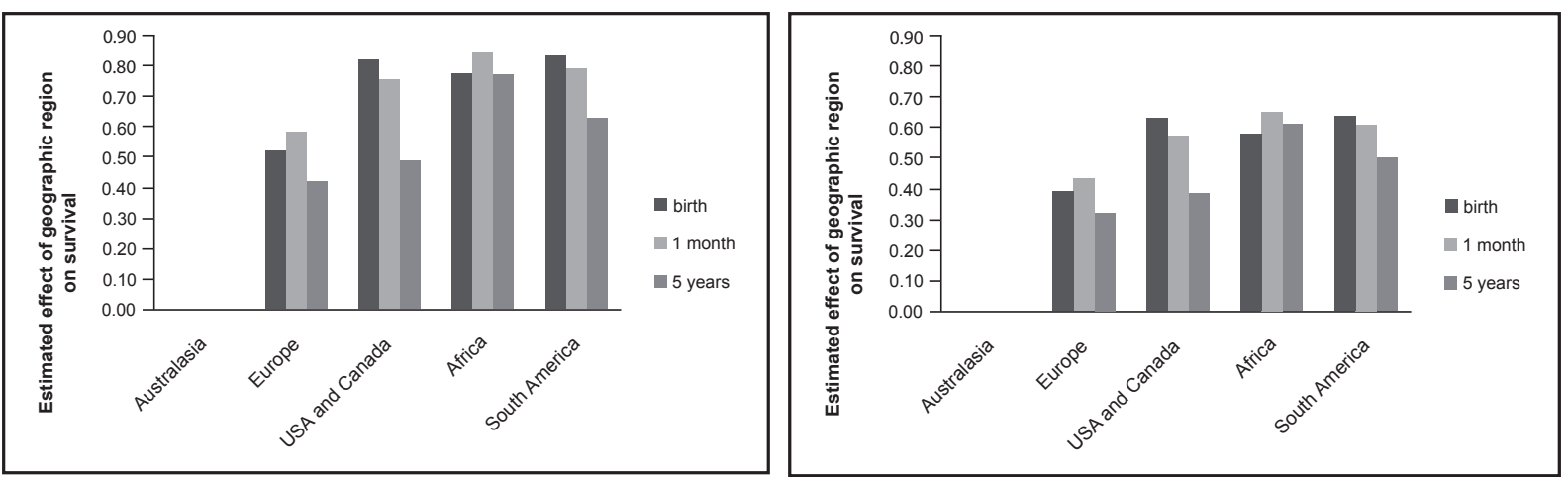

Fig. 2 - Estimated effect of geographic region on survival at birth (0-1 day), survival to 1 month and survival to 5 years of age) with LOGIT (A) or PROBIT (B) transformation in model 1. Africa is the reference region. 
horned (Rhinoceros unicornis) rhinoceros in North America found that the eastern subspecies of black rhinoceros had a skewed offspring sex ratio that favored males (DENNIS et al. 2007). A skewed sex ratio favoring males or females creates difficulties in managing any species in captivity, since there is limited space to house animals not used for breeding purposes, because they simply do not have a mate. Moreover, pygmy hippos are always exhibited as breeding pairs or as single adults (STECK 2015), because those animals avoid living in big groups in nature.

\section{Inbreeding effect}

This study indicated a negative relationship between inbreeding and survival in pygmy hippo, and also that inbreeding primarily affects survival at birth. The significant negative impact of inbreeding on survival in pygmy hippo was also reported by GRACZYK et al. (2015), but it is a known phenomenon for all species in general. As mentioned earlier, inbreeding can cause stillbirths, reduce vitality and increase occurrence of recessive diseases. Traditionally, the genetic management of endangered species in zoological gardens is based on studbook data only, which is useful for the analysis of inbreeding effect. A recent review analysed the pedigree data of 119 zoo populations to assess the effects of inbreeding on various animal species (WITZENBERGER \& HOCHKIRCH 2011) and the results showed that inbreeding depression is very common in zoo populations. However, as the pedigree data were not always complete, the inbreeding effect could be underestimated (WITZENBERGER \& HOCHKIRCH 2011).

In our study, 56 animals did not have parental information in the pedigree that would allow estimation of inbreeding; their inbreeding coefficient was assumed as 0 . This of course can present some bias in this study, however, this assumption was made only for 56 animals out of 1196 used for analysis. Without complete pedigree data of a population, an accurate estimation of inbreeding coefficient is always problematic. There are methods that allow adjusting data in such situations, but for those methods much larger numbers of records are required. For example, VANRADEN (1992) created an algorithm that assigns an average inbreeding from a certain birth year to animals without parents and with this recovers part of the missing parental information. That can work in dairy cattle, when thousands of calves are born each year, whereas in the case of pygmy hippo often only a few new animals are born in a year. If we assume that the inbreeding coefficient of an animal with known parents is assigned to all without parental information it could lead to an overestimation of the inbreeding coefficient. Only the use of genomic information on pygmy hippo would be able to precisely indicate the level of relatedness within the captive population, however, such data is not yet available.

Since 1995 a decreasing trend in the population size of pygmy hippo under managed care has clearly resulted in an increased number of inbred animals. HEDRICK (1992) reported that the mortality rate of inbred animals in captivity was generally greater than that for non-inbred conspecifics. This effect is exacerbated when inbred individuals are also managed in a sub-optimal environment. For example, high levels of inbreeding have been documented in European bison (Bison bonasus); however, this species may experience reduced inbreeding depression when raised in a semi-natural environment (HEDRICK 1992). There are also species for which this generalization does not apply, for example, in greater onehorned rhinos where survival rates are similar for inbred and non-inbred individuals (BAUR \& STUDER 1995). Nonetheless, the majority of inbred animals housed in non-native habitats or stressful captive situations tend to exhibit more inbreeding depression, which is hypothesized to result from genotype by (sub-optimal) environment interaction (HEDRICK 1992). The study of FLACKE et al. (2016) evaluating causes of deaths described a number of reasons for mortality, some of which could also be linked to inbreeding levels in the population, as inbred animals are more susceptible to pathogens and have higher rates of recessive disease than do non-inbred ones. For example, analysis of survival in polycystic kidney disease in 149 individuals, showed that non-inbred animals had a higher chance of survival to 1 year of age than did inbred pygmy hippos, even though the inbreeding itself did not have a significant effect on occurrence of the studied disease (FLACKE et al. 2017). 


\section{Geographic region and its effect}

The environment and climate, or region as described here, is another important factor affecting the survival of pygmy hippo. In this study the region partially represented the breeding programs adopted in different parts of the world: for example, European Endangered Species Programme in Europe and Species Survival Plan in North America. Impact of a breeding program can be a factor affecting survival, not only due to the environmental effects, but also because these programs influence the genetic diversity in captive populations. The results of this study indicated the highest survival rate in Australasia. We hypothesize that the climate and food available in the region are more similar to the natural environment and diet of the pygmy hippo in the wild than they are in Europe and the Americas and, therefore, they contribute to improved survival of this species in captivity. However, the data used in this study did not include any additional information, such as precise climactic factors or specific diet, which would be necessary for further investigation of these hypotheses.

\section{Statistical aspects}

Recently, many approaches have been developed to study survival, e.g., survival analysis (KLEIN \& MOESCHBERGER 2005), which has also been applied to a selected sample of pygmy hippo data (FLACKE 2017). However, mixed models are still most popular, especially when a high number of factors are analysed simultaneously. Thus in our study the mixed model approach was applied with two types of transformation of binominal data.

The proportion of variance explained $\left(\mathrm{R}^{2}\right)$ was used to compare the two models, as the Akaike Information Criterion, log likelihood or Bayesian Information Criterion cannot be applied here. Those parameters apply only when random effects are being changed and not when fixed effects are tested, as in our study. The model with the combined effects of birth period and region resulted in the highest values for $R^{2}$, almost double those seen in the models without combined effects. Based on $R^{2}$ alone, model 2 can be chosen as the best for all three survival time points.

The results presented in this study indicate very low overall $R^{2}$ of applied models. When using binomial data to analyze survival, sample sizes are usually greater than 1500 (OTT \& LONGNECKER 2001), whereas our sample size was 1196. It is, therefore, possible that our sample size was not sufficient for the model to be a good fit for the data.

\section{Plans for the future}

The results of this study indicate that we must exercise vigilance in reducing inbreeding as it negatively impacts survival in the captive pygmy hippo population and most probably also affects the skewness of the sex ratio of this population. Inbreeding control can be achieved by continued efforts to maintain and improve genetic diversity through management of breeding and accompanying transfer of animals between zoological facilities. It is advisable to use as many founders as possible to start a captive breeding program, and it is recommended that these founders are non-inbred and unrelated (WITZENBERGER \& HOCHKIRCH 2011). However, the latest import of a wild animal from West Africa to the breeding program took place in the early 1980 s, which has limited the genetic diversity of captive pygmy hippo for the past 30 years to those living in zoological gardens. The certainty about relationships of the founder stock can only be accurately determined by genomic evaluation of the animals (FLACKE et al. 2015). As this is not easily feasible due to costs of such data collection, current genetic considerations should at least be utilised to control degree of relatedness (based on pedigree records and inbreeding coefficient levels) of the animals selected as breeding pairs, and to remove from the breeding program those females that are most related to the population. 


\section{Acknowledgments}

ESK acknowledges the financial support of Foundation for Polish Science (FNP START 2016 grant no. 94.2016). Authors gratefully acknowledge the helpful comments of scientific editor and anonymous reviewers who contributed to the improvement of this manuscript.

\section{References}

BAUR B. \& STUDER P. (1995). Inbreeding in captive Indian rhinoceros Rhinoceros unicornis. International Zoo Yearbook 34: 205-211. https://doi.org/10.1111/j.1748-1090.1995.tb00680.x

Booy G., Hendriks R.J.J., Smulders M.J.M., VAn Groenendael J.M. \& Vosman B. (2000). Genetic diversity and the survival of populations. Plant Biology 2: 379-395.

https://doi.org/10.1055/s-2000-5958

Dennis P.M., Rajala-Schultz P.J., Funk J.A., Blumer E.S., Miller E.R., Wittum T.E. \& SAVILLE W.J.A. (2007). Risk factors associated with a skewed natal sex ratio in captive black rhinoceroses (Diceros bicorinis) in the United States. Journal of Zoo and Wildlife Medicine 38: 533-539.

https://doi.org/10.1638/MS05-011.1

ELTRINGHAM S.K. (1999). The hippos - Natural history and conservation. Academic Press, London.

Flacke G.L., Chambers B.K., Martin G.B., Paris M.C.J. (2015). The pygmy hippopotamus Choeropsis liberiensis (Morton, 1849): bringing to light research priorities for the largely forgotten. Der Zoologische Garten N.F. 84: 234-265. https://doi.org/10.1016/j.zoolgart.2015.07.006

Flacke G.L., TKalČIĆ S., STECK B., WARREN K., \& MARTIN G.B. (2016). A retrospective analysis of mortality in captive pygmy hippopotamus (Choeropsis liberiensis) from 1912 to 2014. Zoo Biology 35: 556-569. https://doi.org/10.1002/zoo.21336

Flacke G.L., TOMKINS J.L., Black R. \& STECK B. (2017). Demographics of polycystic kidney disease and captive population viability in pygmy hippopotamus (Choeropsis liberiensis). Zoo Biology 36: 136151. https://doi.org/10.1002/zoo.21351

GraczyK M., CWIERTNia P., BorowsKa A., BARCZAK E. \& SzWACZKowsKi T. (2015). Inbreeding and offspring sex ratio in the pygmy hippopotamus (Choeropsis liberiensis) population kept in zoological garden. Folia Biologica (Kraków) 63: 35-42.

HEDRICK P.W. (1992). Genetic conservation in captive populations and endangered species. Pages 4568. In: Jain S.K. \& Botsford L.W. (eds) Applied Population Biology. Kluwer Academic, Dordrecht, The Netherlands.

Klein J.P. \& MoESCHBerger M.L. (2005). Survival analysis: techniques for censored and truncated data. Springer Science \& Business Media.

MAY-COllado J. \& AgnARSSON I. (2011). Phylogenetic analysis of conservation priorities for aquatic mammals and their terrestrial relatives, with a comparison of methods. PLoS One 6: e22562.

Oliehoek P. (2009). Genetic Conservation of Endangered Animal Population. PhD thesis, Wageningen University, The Netherlands.

Ott R.L. \& Longnecker M. (2001). An Introduction to Statistical Methods and Data Analysis. Fifth edition. Duxbury, Thomson Learning.

PluhÁČEK J. \& SteCK B.L. (2015). Different sex allocations in two related species: The case of the extant hippopotamus. Ethology $120: 1-10$. https://doi.org/10.1111/eth.12357

RALLS K. \& BALLOU J. (1986). Captive breeding programs for populations with a small number of founders. Trends in Ecology \& Evolution 1 (1): 19-22. https://doi.org/10.1016/0169-5347(86)90062-5 
Rioux-Paquette E., Festa-Bianchet M. \& Coltman D.W. (2011). Sex-differential effects of inbreeding on overwinter survival, birth date and mass of bighorn lambs. Journal of Evolutionary Biology 24: 121-131. https://doi.org/10.1111/j.1420-9101.2010.02154.x

SARgolzaei M., IWAisaki H. \& ColleaU J.J. (2006). CFC: a tool for monitoring genetic diversity. In: Proceedings of the $8^{\text {th }}$ World Congress on Genetics Applied to Livestock Production, Belo Horizonte, August 13-18 2006: 27-28.

SAS Institute (1999). SAS/STAT User's Guide. SAS Institute Inc., Cary, NC.

SteCK B. (ed.) (2015). Pygmy Hippopotamus Choeropsis liberiensis (Morton, 1844). International Studbook 2014. 21 $1^{\text {st }}$ ed., Zoo Basel, Basel.

SzWACZKOWski T., CYWA-BENKo K., WĘŻYK S. (2003). A note on inbreeding effect on productive and reproductive traits in laying hens. Animal Science Papers and Reports 21: 121-129.

VANRADEN P.M. (1992). Accounting for inbreeding and crossbreeding in genetic evaluation of large populations. Journal of Dairy Science 75.11: 3136-3144.

https://doi.org/10.3168/jds.S0022-0302(92)78077-1

WitZENBERGER K.A. \& HOCHKIRCH A. (2011). Ex situ conservation genetics: a review of molecular studies on the genetic consequences of captive breeding programmes for endangered animal species. Biology and Conservation 20 (9): 1843-1861. https://doi.org/10.1007/s10531-011-0074-4

ZsCHOKKE S. (2002). Distorted sex ratio at birth in captive pygmy hippopotamus (Hexaprotodon liberiensis). Journal of Mammalogy 83: 674-681.

Manuscript received: 29 October 2016

Manuscript accepted: 9 January 2018

Published on: 11 April 2018

Branch editor: Zjef Pereboom 